\title{
Simple $\mu$-Negative Half Mode CRLH Antenna Configuration for MIMO Applications
}

\author{
Mahmoud A. ABDALLA ${ }^{1}$, Ahmed A. IBRAHIM ${ }^{2,3}$ \\ ${ }^{1}$ Dept. of Electronic Engineering, MTC College Cairo, Egypt, \\ ${ }^{2}$ Faculty of Engineering, Minia University, Egypt \\ ${ }^{3}$ Inst. of Micro- and Sensor Systems, University of Magdeburg, Germany \\ maaabdalla@ieee.org, ahmedabdel_monem@mu.edu.eg \\ Submitted August 14, 2016 / Accepted November 28, 2016
}

\begin{abstract}
A design of a compact size mu-negative half mode composite right left handed metamaterial antenna, using only series capacitive loading, for MIMO application is presented. The proposed configuration is simple as it is realized using via free configuration. The MIMO antenna is formed using two antenna elements designed to operate at $5.8 \mathrm{GHz}$ for wireless applications. The overall MIMO antenna size is only $2.6 \times 2.6 \mathrm{~cm}^{2}$ with in-between separation $1.8 \mathrm{~mm}\left(0.034 \lambda_{0}\right)$. Moreover, the ports mutual coupling reduction between the two antenna elements, achieved without using extra structure, is lower than $-20 \mathrm{~dB}$. Compared to conventional two microstrip patch MIMO antennas, our proposed configuration has more than 50\% size reduction and $9 \mathrm{~dB}$ enhancement in the mutual coupling for the same separation. The antenna design principles, full wave simulations, experimental measurements are introduced with good agreement. Finally, MIMO parameters are extracted and discussed.
\end{abstract}

\section{Keywords}

Metamaterial, MIMO antenna, composite right left handed transmission line, isolation enhancement

\section{Introduction}

Left handed metamaterials (LHMs) have gained great interest in past few years in RF/microwave circuit applications. They have been realized in planar transmission line approach, which is basically based on loading a transmission line (TL) with series capacitors and shunt inductors. This transmission line is used to be called a composite right left handed (CRLH) TL [1] or negative refractive index (NRI) TL [2]. Mainly these TLs are characterized by backward waves whose propagation consonant is non-linear, frequency dependent and engineered characteristic impedance. Based on these properties, many compact and multi-band novel antennas have been proposed in the literature by several groups [3-13]. The need for different properties has encouraged the researchers to introduce different configurations of CRLH cell by increasing its order such as extended CRLH TL [14], generalized NRI TL [15], [16]. However, these approaches increase the opportunity for more multi band at the expense of increasing the design complexity. On the other hand, it has been pointed out that Epsilon-negative and Mu-negative structures have imaginary propagation constants such that they have a band stop resonance properties [17], [18]. Consequently, they have been applied in many antennas realizations employing Epsilon-negative [19], [20] and Mu-negative [21], [22]. These structures are simpler than conventional CRLH cells and easier in design.

In the MIMO system, two or more antennas are used on both the transmitter and receiver sides to enhance the channel capacity [23], [24]. However, closely-spaced antenna elements suffer from severe degradation in their diversity performance; due to mutual coupling among the antenna elements. Therefore, reducing the mutual coupling between antenna elements is essential for better performance of MIMO systems. Several works have been carried out to reduce the mutual coupling effect between antenna elements in MIMO systems such as using electromagnetic band gap structures [25]. Also, using defected ground structures (DGSs) etched in different shapes in the ground plane has been employed [26], [27]. However, these structures suffer from complexity and large size. Therefore, different attempts to enhance the isolation have been suggested [28], [29]. Recently, it has been suggested that the different antenna orientations for current reversal can reduce the mutual coupling problem [30-32].

In this paper, we introduce a new two elements metamaterial MIMO antenna. The antenna element is constructed as a Mu-negative resonant structure. The realization has been suggested as half mode realization of CRLH cell by employing series capacitive load only. The proposed MIMO antenna has a compact size and very low coupling isolation without using extra structure. The performance of the designed MIMO antenna has been validated using the electromagnetic full wave simulations. Finally, the simulated results are confirmed by experimental measurements. 


\section{Half Mode CRLH MIMO Antennas}

\subsection{Half Mode CRLH Antenna Concept}

The CRLH transmission line resonating antenna is based on open circuit termination of one or more CRLH cells as shown in Fig. 1(a). In the figure, $L_{\mathrm{L}}$ and $C_{\mathrm{L}}$ are corresponding to the loading shunt inductor and series capacitor whereas $L_{\mathrm{R}}$ and $C_{\mathrm{R}}$ are corresponding to the patristic element of the loaded transmission line. For $N$ CRLH cells, the design condition for the antenna is to achieve integer multiple of half wave progressive phase. This can be expressed in terms of a constant integer $n$, the total antenna physical length $d$, and the guided propagation constant as

$$
\text { phase }=N \beta d=n \pi \text {. }
$$

where $\beta$ is the propagation constant along the CRLH TL, defined as

$$
\cos (\beta d)=1-\frac{\omega^{2}}{2}\left(\left(L_{\mathrm{R}}-\frac{1}{\omega^{2} C_{\mathrm{L}}}\right)\left(C_{\mathrm{R}}-\frac{1}{\omega^{2} L_{\mathrm{L}}}\right)\right)
$$

Balanced CRLH TL has a continuous passband with no stopband between the right and left handed pass bands. The transition frequency between the two bands is associated with zero propagation constant $\beta$. It has been shown in [33], [34] that the resonance frequency of the zeroth order antenna is either the shunt branch resonance frequency $f_{\mathrm{sh}}$ or the series branch resonance frequency $f_{\text {se }}$ which are identical. However, it has been explained that for the open circuit resonance mode of the zeroth order mode CRLH antenna, the energy storage is within the shunt branch. The resonant frequencies for the shunt branch $f_{0 \text { sh }}$ and the series branches $f_{0 \text { se }}$ can be written as

$$
\begin{aligned}
& f_{0 \mathrm{sh}}=\frac{1}{2 \pi \sqrt{L_{\mathrm{L}} C_{\mathrm{R}}}}, \\
& f_{0 \mathrm{se}}=\frac{1}{2 \pi \sqrt{L_{\mathrm{R}} C_{\mathrm{L}}}} .
\end{aligned}
$$

Based on this fact, in case of employing such antenna in MIMO system to reduce the mutual coupling between antenna elements, it is suggested in this paper to design the open circuit antenna element as shown in Fig. 1(b). In other words, the half mode cell is suggested to be realized using the series combination only $\left(C_{\mathrm{L}}\right.$ and $\left.L_{\mathrm{R}}\right)$. Thanks to this configuration, the energy storage will be minimized and eliminated and hence the mutual coupling will be reduced. Also, this structure is simpler than full CRLH case since it does not require a shunt inductance.

\subsection{Microstrip Half Mode CRLH MIMO Antenna Structure}

The 2D layout of the half mode single cell CRLH metamaterial antenna is illustrated in Fig. 2. The antenna is

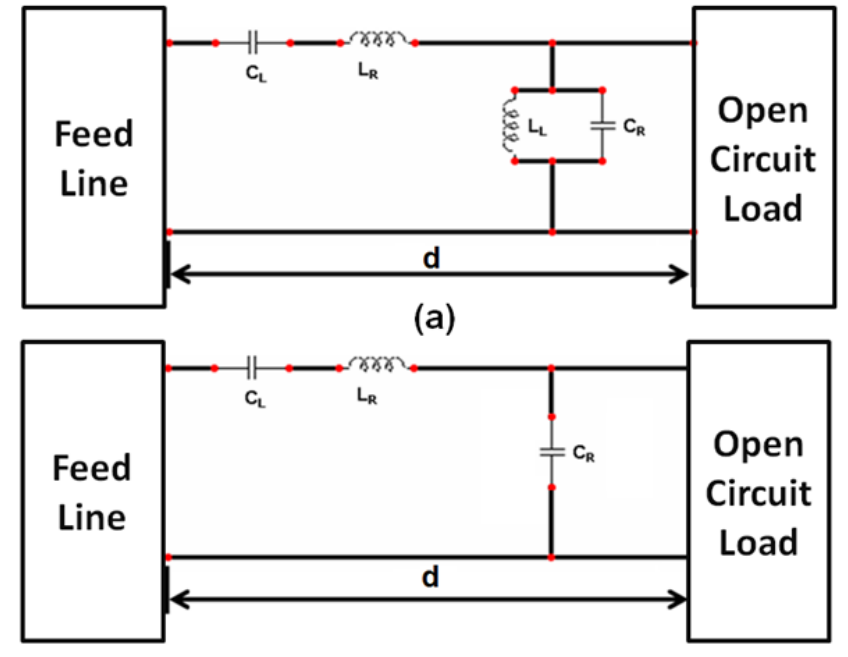

(b)

Fig. 1. The equivalent circuit model of the CRLH TL antenna: (a) The full mode case. (b) The practical mu-negative half mode.

formed from series interdigital capacitors $C_{\mathrm{L}}$ and two parasitic elements which are corresponding to the $\mathrm{RH}$ parameters (the series inductor $L_{\mathrm{R}}$ and the shunt capacitor $C_{\mathrm{R}}$ ). The proposed configuration is simple since it needs no via connection to the ground. The antenna is printed on FR4 substrate with relative permittivity of 4.4 , a dielectric loss tangent of 0.025 and thickness of $1.6 \mathrm{~mm}$.

The single antenna element is arranged in a two-elements MIMO configuration whose 2D layout is shown in Fig. 3(a). A comparison between the suggested half mode CRLH MIMO antenna and the conventional patch antenna have been established. The 2D layout of two elements patch MIMO antenna is shown in Fig. 3(b). As shown in the figure, the distance between the edges of two antenna elements is only $1.8 \mathrm{~mm}$ which equals $0.034 \lambda_{0}$ at $5.8 \mathrm{GHz}$ in both cases. From Fig. 3, it can be observed that the proposed antenna has compact size $\left(26 \times 26 \mathrm{~mm}^{2}\right)$ but the twoelements patch antenna have size of $\left(54 \times 30 \mathrm{~mm}^{2}\right)$ which is more than double size of the proposed one in Fig. 3(a).

The geometrical design of the antenna layout was done by calculating the loading element $C_{\mathrm{L}}$ in (4) so that the antenna has a resonance at $5.8 \mathrm{GHz}$. Then $C_{\mathrm{L}}$ was

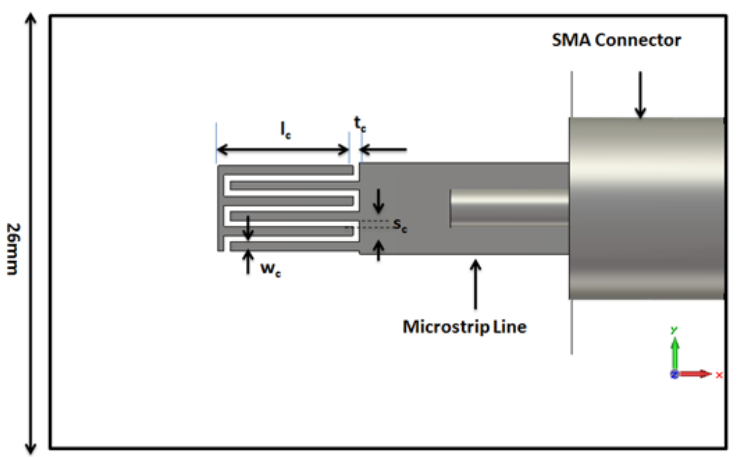

Fig. 2. The 2D layout of single cell half mode CRLH antenna, finger width $\left(W_{\mathrm{c}}=0.2 \mathrm{~mm}\right)$ and separation $\left(S_{\mathrm{c}}=\right.$ $0.2 \mathrm{~mm}),\left(t_{\mathrm{c}}=0.2 \mathrm{~mm}\right)$. 


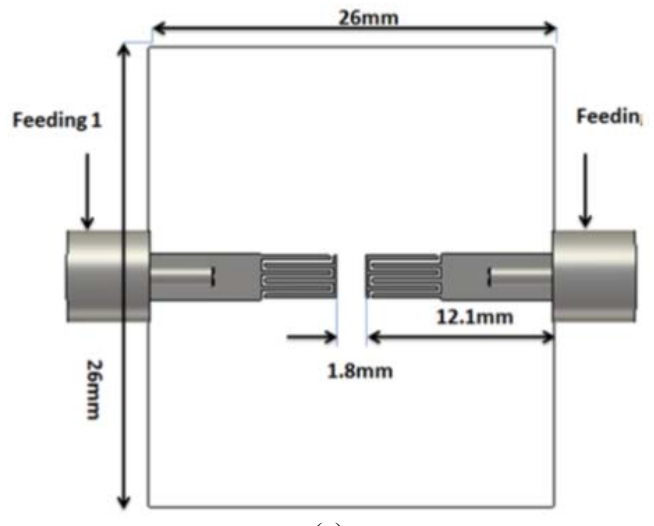

(a)

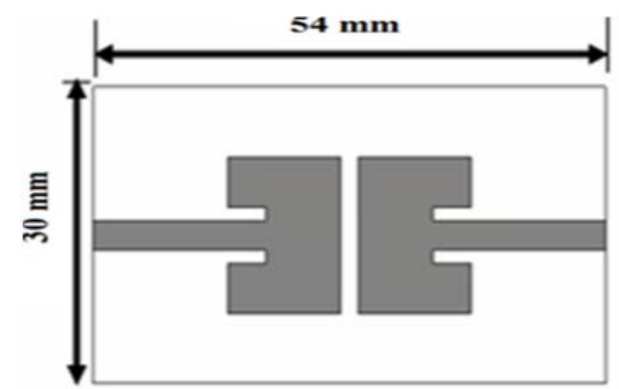

(b)

Fig. 3. The 2D layout of (a) half mode CRLH MIMO antenna, $s=1.8 \mathrm{~mm}$, (b) the two elements patch MIMO antenna with separation equal to $1.8 \mathrm{~mm}$.

realized as interdigital capacitor. This can be expressed mathematically as [1]

$$
C=3.937 \times 10^{-5} l_{\mathrm{f}}\left(\varepsilon_{\mathrm{r}}+1\right)(0.11(n-3)+0.252)[\mathrm{pF}]
$$

where $l_{\mathrm{f}}$ is the capacitor finger length, $n$ is the capacitor number of fingers. The capacitor width and spacing were selected to match the $50 \Omega$ feeding microstrip transmission line width. The right handed inductor was specified by the patristic inductance of the whole cell length. The design of the proposed MIMO antenna was validated by studying the scattering parameter magnitudes. As shown in Fig. 4(a), the antenna operates at $5.8 \mathrm{GHz}$ at which the return loss is lower than $-10 \mathrm{~dB}$ approximately; similar results for patch MIMO antenna are observed. On the other hand, the mutual coupling of the half mode MIMO antenna in terms of the transmission coefficient $S_{21}$ magnitude equals $-21 \mathrm{~dB}$ as shown in Fig. 4(b) whereas it is $-12 \mathrm{~dB}$ in patch MIMO antenna. Compared to the proposed half mode CRLH MIMO antenna, we can claim that the proposed configuration has $9 \mathrm{~dB}$ enhancements in the isolation between the two output ports.

\section{Half Mode CRLH MIMO Antenna Performance}

The evaluation performance of the half mode CRLH MIMO antenna is done by investigating the envelope correlation, the diversity gain, and total active reflection coefficient (TARC). When the correlation between two antenna elements is low, the diversity gain is high and vice versa. Therefore, the correlation between two antenna elements has to be as low as possible to achieve high performance in MIMO system. The envelope correlation of stub free MIMO antenna is shown in Fig. 5. It is noticed that the envelope correlation coefficient equals $0.02(-34 \mathrm{~dB})$ at $5.8 \mathrm{GHz}$. The relationship between the envelope correlation and the diversity gain has been calculated as [35]

$$
\begin{gathered}
\rho_{\mathrm{e}}=\frac{\left|S_{11}^{*} S_{12}+S_{21}^{*} S_{22}\right|^{2}}{\left(1-\left(\left|S_{11}\right|^{2}+\left|S_{21}\right|^{2}\right)\right)\left(1-\left(\left|S_{22}\right|^{2}+\left|S_{12}\right|^{2}\right)\right)}, \\
G a p p=10 \sqrt{1-|\rho|} \text { where } \rho_{\mathrm{e}}=|\rho| .
\end{gathered}
$$

The diversity gain of the stub free MIMO antenna is illustrated in Fig. 6. It is clear that the diversity gain of the antenna equals 9.89 .

The last parameter used to measure the performance of the MIMO antenna is TARC. TARC is defined as the ratio of the square root of the total reflected power divided by the square root of the total incident power. The TARC meaning can be defined as the return loss of the whole MIMO antenna elements. The TARC has been calculated from the scattering parameters of a two antenna elements as [35]
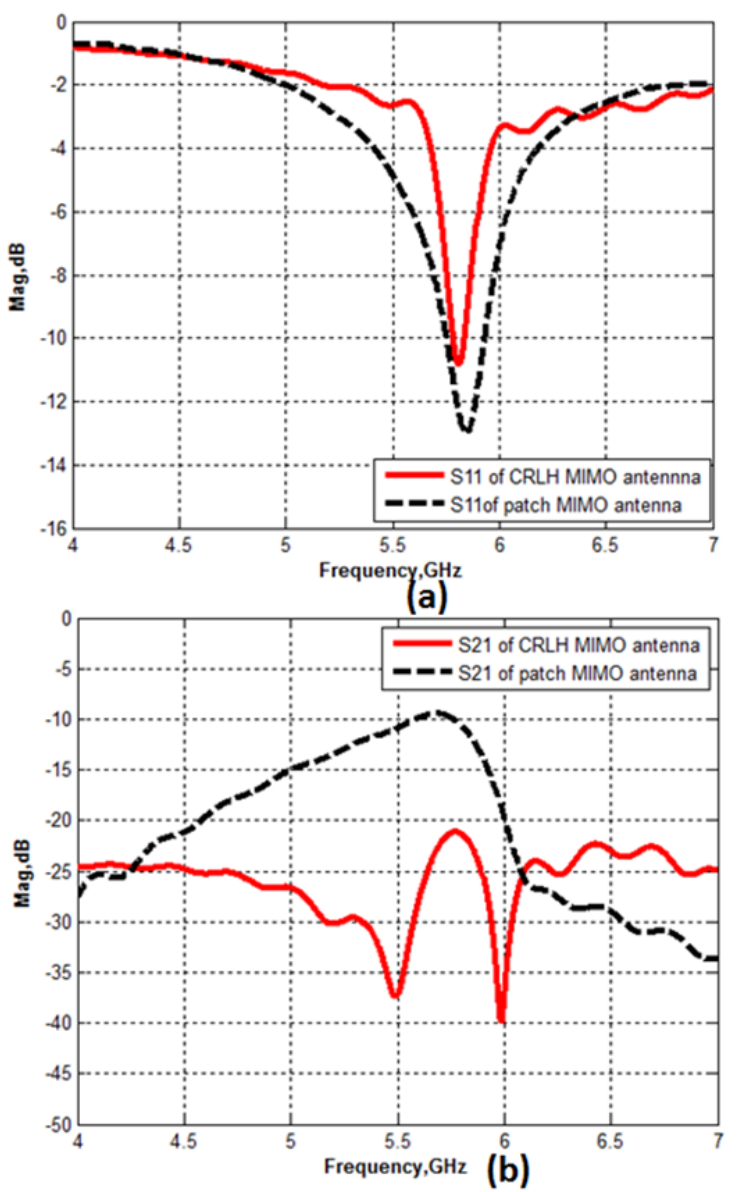

Fig. 4. The scattering parameter magnitudes of simulated results of half mode CRLH MIMO antenna and patch MIMO antenna: (a) $S_{11}$, (b) $S_{21}$. 


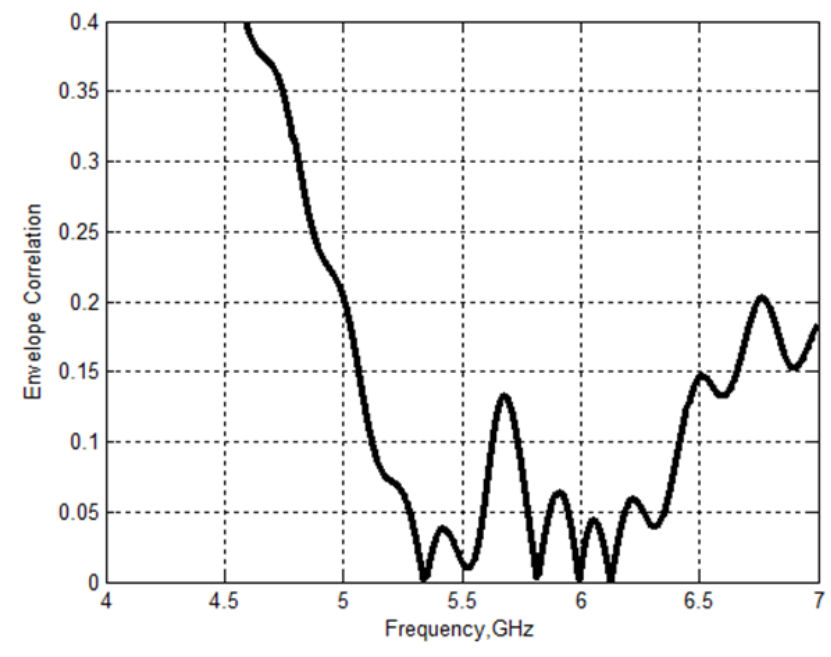

Fig. 5. The envelope correlation coefficient of the half mode CRLH MIMO.

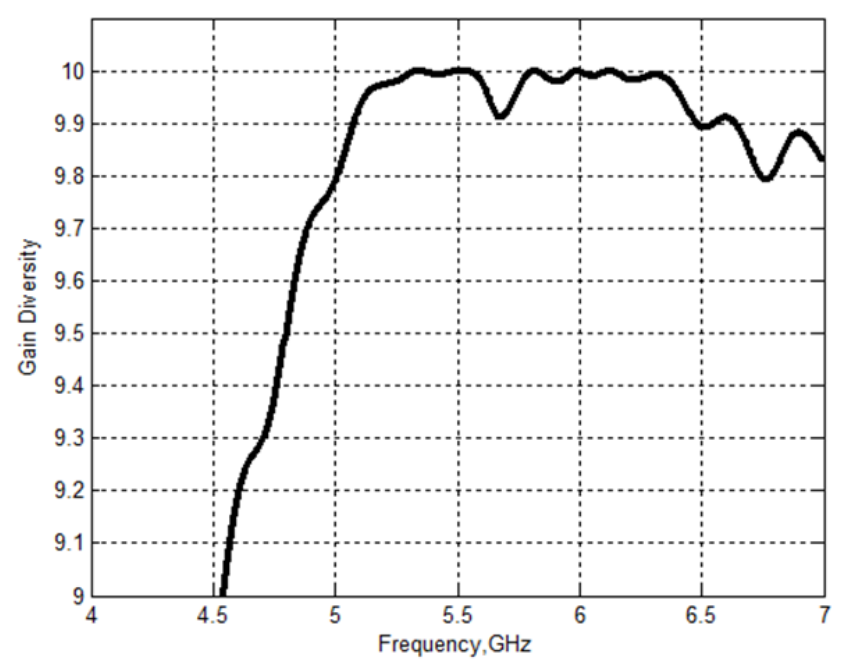

Fig. 6. The diversity gain of the half mode CRLH MIMO antenna.

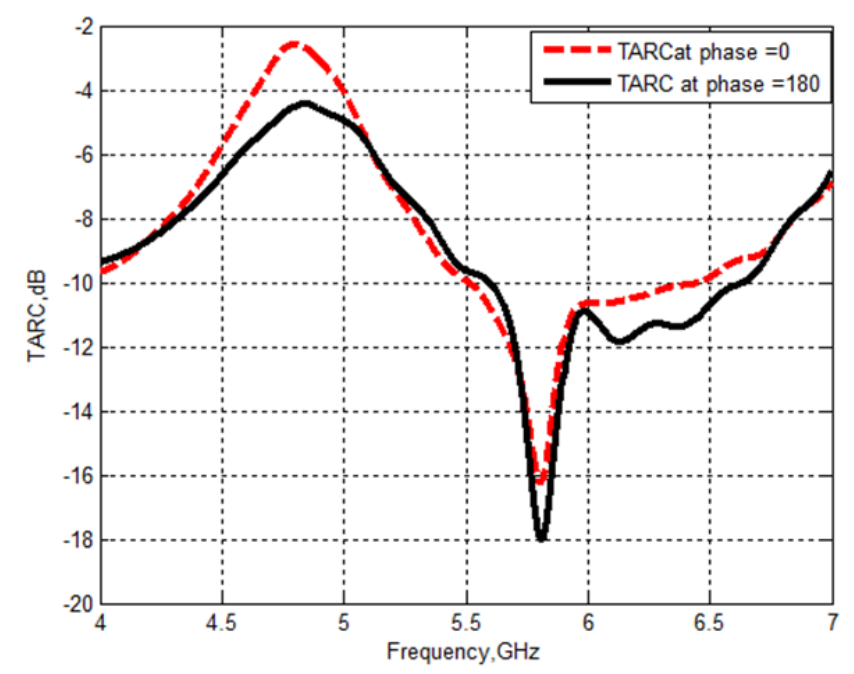

Fig. 7. The TARC of the half mode CRLH MIMO antenna.

$T A R C=\sqrt{\frac{\left|S_{11}+S_{12} \exp (\mathrm{j} \theta)\right|^{2}+\left|S_{21}+S_{22} \exp (\mathrm{j} \theta)\right|^{2}}{2}}$ where $\theta$ is considered variable angle which is related to the phase of excitation signal. A random phased excitation vectors have been used to calculate average TARC and the MIMO channel is assumed to be Gaussian and multipath spread in the propagation channel. TARC is calculated at each random phase between $0^{\circ}$ and $180^{\circ}$. However, only two phases $0^{\circ}$ and $180^{\circ}$ are demonstrated as shown in Fig. 7. It is obvious that from Fig. 7 the two MIMO antennas demonstrate the same TARC with two used phases $0^{\circ}$ and $180^{\circ}$ which equals $-18 \mathrm{~dB}$.

\section{Experimental Results}

The photograph of the fabricated MIMO antenna printed on FR4 substrate is shown in Fig. 8. The simulated and measured scattering parameter magnitudes are shown in Fig. 9. It is clear from the simulated results that the return loss is more than $-10 \mathrm{~dB}$ and the mutual almost $-21 \mathrm{~dB}$. The measured results illustrate that there are small frequency shifts between the measured and simulated results. The return loss is $13 \mathrm{~dB}$ at $5.9 \mathrm{GHz}$ and the mutual coupling equals $-15 \mathrm{~dB}$. The small shift in frequency beween the simulated and measurement results is due to the

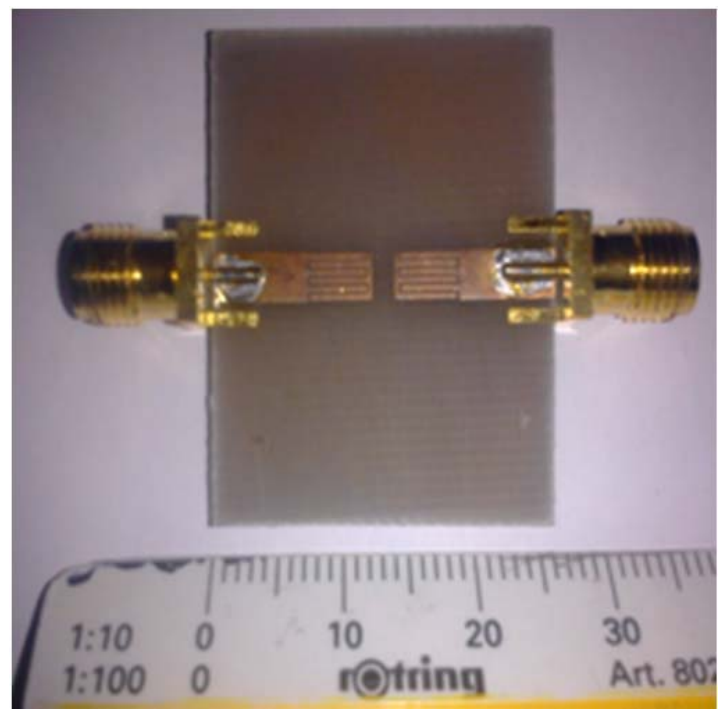

Fig. 8. Photograph of the fabricated half mode CRLH MIMO antenna.

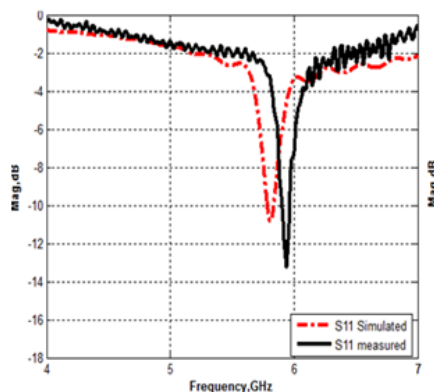

(a)

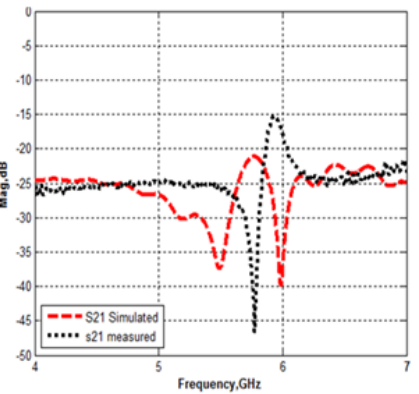

(b)
Fig. 9. The simulated and measured scattering parameter magnitudes of the half mode CRLH MIMO antenna: (a) $S_{11}$ results, (b) $S_{21}$ results. 


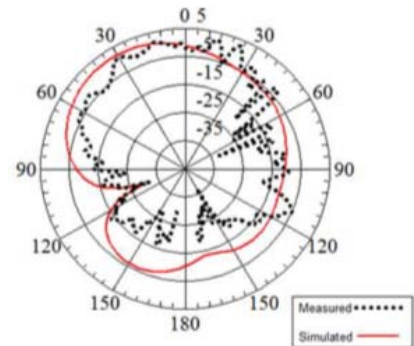

(a)

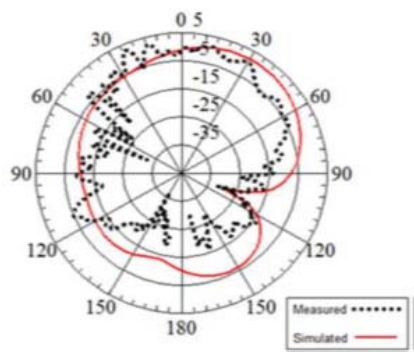

(c)

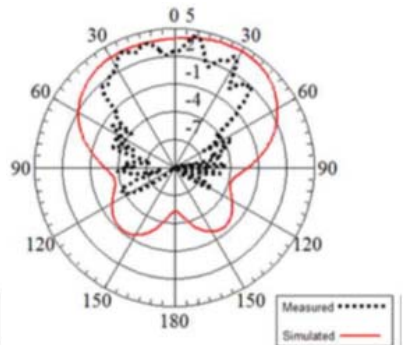

(b)

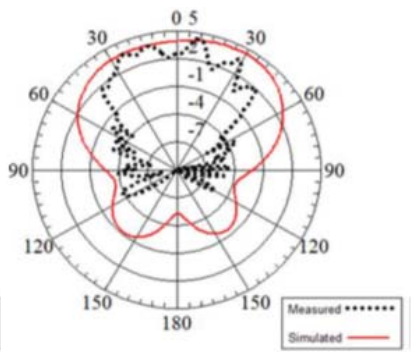

(d)
Fig. 10. The simulated and measured directive gain of half mode CRLH MIMO antenna at $5.8 \mathrm{GHz}$ : (a) E plane at port 1 , (b) $\mathrm{H}$ plane at port 1 , (c) E plane at port 2, (d) $\mathrm{H}$ plane at port 2.

imperfection of full wave simulation conditions and the fabrication accuracy which cannot be totally avoided. However, it can be still considered a good agreement between the simulated and measured results is achieved.

The measurements of antenna radiation pattern have been done inside an anechoic chamber. The simulated and measured directive gain pattern in both $\mathrm{E}(X Z)$ and $\mathrm{H}(Y Z)$ planes of the half mode MIMO antenna are shown in Fig. 10. This was obtained assuming the excitation at port 1 and port 2, respectively, while other port is matched. It is obvious that a good agreement is achieved between the measured and simulated results. Finally, we can conclude that the introduced antenna patterns confirm that the proposed antenna can be used for various wireless communication applications. The simulated efficiency of the proposed antenna equals $45 \%$. This relatively small efficiency is due to the compact microstrip size and losses introduced by the used FR4 substrate.

\section{Conclusion}

A design of a mu-negative half mode CRLH MIMO based antenna has been introduced. The MIMO antenna consists of two antenna elements which operate at $5.8 \mathrm{GHz}$ for wireless applications. The distance between the edges of two antenna elements has been achieved to be only $0.034 \lambda_{0}$. Also, less than $-20 \mathrm{~dB}$ mutual coupling between two antenna elements has been achieved with current reversal and without using any extra complicated structure. The proposed MIMO antenna has the advantage of compactness (its size is only $2.6 \times 2.6 \mathrm{~cm}^{2}$ ). A good agreement has been achieved between simulated and measured results. The retrieved MIMO performance parameters proved low correlation coefficient, high diversity gain and small TARC.

\section{References}

[1] CALOZ, C., ITOH, T. Electromagnetic Metamaterials Transmission Line Theory and Microwave Applications. New Jersey: John Wiley, 2006. DOI: 10.1002/0471754323

[2] ELEFTHERIADES, G. V., BALMAIN, K. G. Negative Refraction Metamaterials. New Jersey: John Wiley, 2005. ISBN: 978-0-47160146-3

[3] CHENG-JUNG LEE, WEI HUANG, GUMMALLA, A., et al. Small antennas based on CRLH structures: Concept, design, and applications. IEEE Antennas and Propagation Magazine, 2011, vol. 53, no. 2, p. 10-25. DOI: 10.1109/MAP.2011.5949321

[4] ZIOLKOWSKI, R. W., JIN, P., LIN, C. Metamaterial-inspired engineering of antennas. Proceedings of the IEEE, 2011, vol. 99, no. 10 , p. 1720-1731. DOI: 10.1109/JPROC.2010.2091610

[5] DONG, Y., ITOH, T. Metamaterial-based antennas. Proceedings of the IEEE, 2012, vol. 100, no. 7, p. 2271-2285. DOI: 10.1109/JPROC.2012.2187631

[6] ZHU, J., ANTONIADES, M. A., ELEFTHERIADES, G. V. A compact tri-band monopole antenna with single-cell metamaterial loading. IEEE Transactions on Antennas and Propagation, 2010 vol. 58, no. 4, p. 1031-1038. DOI: 10.1109/TAP.2010.2041317

[7] BARBUTO, M., BILOTTI, F., TOSCANO, A. Design of a multifunctional SRR-loaded printed monopole antenna. International Journal of RF and Microwave Computer-Aided Engineering, 2012, vol. 22, no. 4, p. 552-557. DOI: $10.1002 /$ mmce. 20645

[8] JIN, P., LIN, C. C., ZIOLKOWSKI, R. W. Multifunctional, electrically small, planar near-field resonant parasitic antennas. IEEE Antennas and Wireless Propagation Letters, 2012, vol. 11 p. 200-204. DOI: 10.1109/LAWP.2012.2187322

[9] BARbuto, M., TrotTA, F., BilotTi, F., TOSCANO, A. Design of a low-profile antenna by using orthogonal parasitic meandered monopoles. Progress In Electromagnetics Research Letters, 2015, vol. 55, p. 23-29. DOI: 10.2528/PIERL15061903

[10] LI XUE, JINWEN TIAN. Low-profile fully-printed multifrequency monopoles loaded with complementary metamaterial transmission line. Radioengineering, 2015, vol. 24, no. 1, p. 64-69. DOI: 10.13164/re.2015.0064

[11] VRBA, D., POLIVKA, M. Radiation efficiency improvement of zeroth-order resonator antenna. Radioengineering, 2009, vol. 18, no. 1, p. $1-8$.

[12] UGARTE-MUNOZ, E., HERRAIZ-MARTÍNEZ, F. J., GONZALEZ-POSADAS, V., et al. Patch antenna based on metamaterials for a RFID transponder. Radioengineering, 2008, vol. 17, no. 2, p. 66-71.

[13] WAHBA, W., ABDAllA, M. A., ALlAM, A. M. Experimental verification of a compact zeroth order metamaterial substrate integrated waveguide antenna. Progress in Electromagnetic Research C, 2016, vol. 67, p. 193-201. DOI: 10.2528/PIERC16052906

[14] RENNINGS, A., OTTO, S., MOSIG, J., et al. Extended composite right/left-handed (E-CRLH) metamaterial and its application as quadband quarter-wavelength transmission line. In Asia-Pacific Microwave Conference (APMC). Yokohama (Japan), 2006, p. 1405-1408. DOI: 10.1109/APMC.2006.4429669

[15] RYAN, C. G. M., ELEFTHERIADES, G. V. Design of a printed dual-band coupled-line coupler with generalised negativerefractive index transmission lines. IET Microwaves, Antennas and Propagation, 2012, vol. 6, p. 705-712. DOI: 10.1049/ietmap.2011.0508

[16] FOUAD HAGAG, M. A., ABDALLA, M. A. Ultra compact CPW dual band filter based on П-generalized metamaterial NRI transmission line. Journal of Electromagnetic Waves and Applications, 2015, vol. 29, no. 8, p. 1093-1103. DOI: $10.1080 / 09205071.2015 .1044123$ 
[17] ALÙ, A., ENGHETA, N. Pairing an epsilon-negative slab with a mu-negative slab: resonance, tunneling and transparency. IEEE Transactions on Antennas and Propagation, 2003, vol. 51, no. 10 , p. 2558-2571. DOI: 10.1109/TAP.2003.817553

[18] ABDALLA, M. A., HU, Z. Nonreciprocal left handed coplanar waveguide over ferrite substrate with only shunt inductive load. Microwave and Optical Technology Letters, 2007, vol. 49, p. 2810-2814. DOI: $10.1002 / \mathrm{mop} .22848$

[19] PARK, J.-H., RYU, Y.-H., LEE, J.-G., LEE, J.-H. Epsilon negative zeroth-order resonator antenna. IEEE Transactions on Antennas and Propagation, 2007, vol. 55, no. 12, p. 3710-3712. DOI: 10.1109/TAP.2007.910505

[20] ABDAlla, M. A., FOUAD, M., A., AHMED, A., ZHIRUN HU. A new compact microstrip triple band antenna using half mode CRLH transmission line. In 2013 IEEE International Antennas and Propagation Society International Symposium Digest (APSURSI). Orlando (USA), Jul. 2013, p. 634-635. DOI: 10.1109/APS.2013.6710977

[21] KUNPENG WEI, ZHANG, Z., FENG, Z., et al. A wideband MNG-TL dipole antenna with stable radiation patterns. IEEE Transactions on Antennas and Propagation, 2013, vol. 61, no. 5, p. 2418-2424. DOI: 10.1109/TAP.2013.2241717

[22] SIMORANGKIR, R., LEE, Y. A planar dual-band periodic leakywave antenna based on a mu-negative (MNG) transmission line. IEEE Transactions on Antennas and Propagation, 2015, vol. 63, no. 5, p. 2370-2374. DOI: 10.1109/TAP.2015.2410802

[23] PAUlRAJ, A. J., GORE, D. A., NABAR, R. U., BOLCSKEI, H. An overview of MIMO communications - A key to gigabit wireless. Proceedings of the IEEE, 2004, vol. 92, no. 2, p. 198 to 217. DOI: 10.1109/JPROC.2003.821915

[24] DIOUM, I., CLEMENTE, M., DiAllo, A., LUXEY, C., et al. Meandered monopoles for $700 \mathrm{MHz}$ LTE handsets and improved MIMO channel capacity performance. Radioengineering, 2011, vol. 20, no. 4, 2011, p. 726-732.

[25] KIM, S.-H., LEE, J.-Y., NGUYEN, T. T., JANG, J.-H. High-performance MIMO antenna with 1-D EBG ground structures for handset application. IEEE Antennas and Wireless Propagation Letters, 2013, vol. 12, p. 1468-1471. DOI: 10.1109/LAWP.2013.2288797

[26] IBRAHIM, A. A., ABDAlla, M. A., ABDEL-RAHMAN, A. B., et al. Compact MIMO antenna with optimized mutual coupling reduction using DGS. International Journal of Microwave and Wireless Technologies, 2014, vol. 6, no. 2, p 173-180. DOI: $10.1017 / \mathrm{S} 1759078713001013$

[27] ADDACI, R., DIALLO, A., LUXEY, C., et al. Design of multiantenna system for UMTS clamshell mobile phones with ground plane effects considerations. Radioengineering, 2014, vol. 23, no. 2, p. 724-732.

[28] SHARAWI, M. S., NUMAN, A. B., KHAN, M. U., et al. A dualelement dual-band MIMO antenna system with enhanced isolation for mobile terminals. IEEE Antennas and Wireless Propagation Letters, 2012, vol. 11, p. 1006-1009. DOI: 10.1109/LAWP.2012.2214433

[29] ABDAlla, M. A., ABDElrahEEM, A. Compact transmit receive hybrid electromagnetic isolation in antenna array transceiver system for full duplex applications. IET Microwaves, Antennas and Propagation, 2016. DOI: 10.1049/ietmap.2016.0215

[30] ABDAlla, M. A., IBRAHIM, A. A. Design of close, compact, and high isolation meta-material MIMO antennas. In 2013 IEEE International Antennas and Propagation Society International
Symposium Digest (APSURSI). Orlando (USA), Jul. 2013, p. 186 to 187. DOI: $10.1109 /$ APS.2013.6710754

[31] IBRAHIM, A. A., ABDALLA, M. A. CRLH MIMO antenna with reversal configuration. AEU-International Journal of Electronics and Communications, 2016, vol. 70, p. 1134-1141. DOI: 10.1016/j.aeue.2016.05.012

[32] ABDALLA, M. A., IBRAHIM, A. A. Design and performance evaluation of metamaterial inspired MIMO antennas for wireless applications. Wireless Personal Communications, 2016, p. 1-17. DOI: $10.1007 / \mathrm{s} 11277-016-3809-4$.

[33] RENNINGS, A., LIEBIG, T., CALOZ, C., WALDOW, P. MIM CRLH series mode zeroth order resonant antenna (ZORA) implemented in LTCC technology. In Asia-Pacific Microwave Conference (APMC 2007). 2007, p. 1-4. DOI: 10.1109/APMC.2007.4554577

[34] ABDALlA, M. A., ZHIRUN HU, MUVIANTO, C. Analysis and design of triple band metamaterial simplified CRLH cells loaded monopole antenna. International Journal of Microwave and Wireless Technologies, June 2016, p. 1-11. DOI: $10.1017 / \mathrm{S} 1759078716000738$

[35] TOKTAS, A., AKDAGLI, A. Compact multiple-input multipleoutput antenna with low correlation for ultra-wide-band applications. IET Microwaves, Antennas and Propagation, 2015, vol. 9, no. 8, p. 822-829. DOI: 10.1049/iet-map.2014.0086

\section{About the Authors ...}

Mahmoud ABDALLA was born in 1973. He received the M.Sc. degree in Electrical Engineering from the Military Technical College in 2000, and the Ph.D. degree from the Microwave and Communication Group, School of Electrical Engineering, Manchester University, UK, in 2009. His research includes microwave/ millimeter components, miniaturized multiband antennas/wideband antennas, electromagnetic energy harvesting systems, smart antenna systems for DOA estimation and interference cancellations, metamaterial/EBG structures. Also, his work is oriented into MIMO antenna with better performance. Under these directions, Dr. Abdalla has published more than 100 journal / conference papers.

Ahmed A. IBRAHIM was born in 1986. He received the B.Sc. degree, with grade of very good, in Electrical Engineering from the Electronic and Communication Engineering Department, Elminia University, Elminia, Egypt in 2007. He was awarded the M.Sc. degree in Electronic and Communication Engineering from Elminia University in 2011, and the Ph.D. degree in Electronic and Communication Engineering from Elminia University in 2014. He is now post-doctoral fellow in the Otto-von-Guericke-Universität Magdeburg,Germany. Also he is a lecturer in Electronic and Communication Engineering Department. His research focused on the design and analysis of microstrip antennas, microstrip filters, and their application in wireless communications, also on metamaterial MIMO antennas and different metamaterial applications in microwave bands. 